\title{
COMFORT AND THE PEDESTRIAN ENVIRONMENT - ADOPTING A QUALITATIVE APPROACH - ANALYSIS OF PEDESTRIAN NETWORKS IN ADYAR, CHENNAI.
}

\author{
Rakesh K.S. , Abdul Razak Mohamed ${ }^{2}$ \\ ${ }^{1}$ Research Scholar, School of Architecture and Planning, Anna University, Chennai, India \\ ${ }^{2}$ School of Architecture and Planning, Anna University, Chennai, India \\ E-mail : 'ksrakeshnair@gmail.com
}

\begin{abstract}
Pedestrian spaces are becoming increasingly rare nowadays. The explosive increase in vehicular traffic has relegated the pedestrian to subways and over bridges. Various studies have demonstrated the benefits that could accrue to a city by the creation of proper pedestrian. The Indian Roads Congress (IRC) has stipulated standards for pedestrian facilities. But, Pedestrian amenities, street furniture and context-specific standards according to the location, hierarchy and functions of streets have not been thought of. The quality of the walking environment is a subject which has seen comparatively little study and analysis vis-à-vis other modes of transportation. Qualitative evaluation could be used to judge comfort requirements to increase efficient use of the pedestrian network.
\end{abstract}

Key words: Pedestrian Spaces, Qualitative Evaluation, Standards, Adyar

\section{BACKGROUND}

A casual walk through a busy Chennai road would quickly dispel all notions of a human/pedestrian-friendly city. Astreet here offers almost nothing to a pedestrian. Not in scale, not in detail and certainly not in pedestrian facilities and amenities. Basically a comfortable human environment is one which is to human scale, not that of fast plying vehicles. The perception of buildings at eye-level close to people walking about is very important. It is at this level that we achieve or fail to achieve human scale in a place.

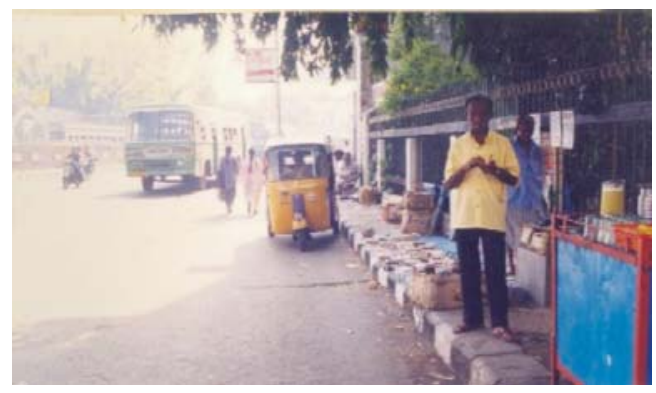

Fig. 1. Mount Road - Obstacles faced by pedestrians

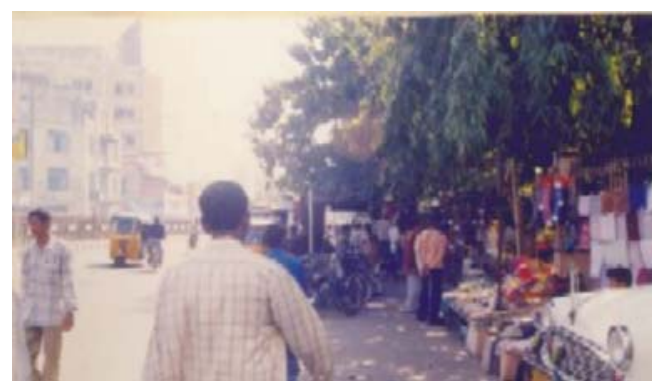

Fig. 2. Encroachment on sidewalks
Francis Tibbalds in his classic "Making peoplefriendly towns" very cogently puts forth the argument that places matter much more than either individual buildings or vehicular traffic. Successful and attractive cities are also characterized by a variety and mix of uses and activities in one area, as opposed to the modern principles of horizontal separation of use and activity. The best urban places offer a mixture of uses and a variety of activities and experiences.

"The freedom with which a person can walk about and look around is a very useful guide to the civilized quality of an urban area." (Buchanan, Sir Colin 1963)

Five decades later the pedestrian is still being given quite a raw deal in most urban areas. Accidents, pollution, unfavorable traffic signals, obstacles to walking on pavements, the ever-increasing number of cars and large and slab-like buildings that block pedestrian movement.

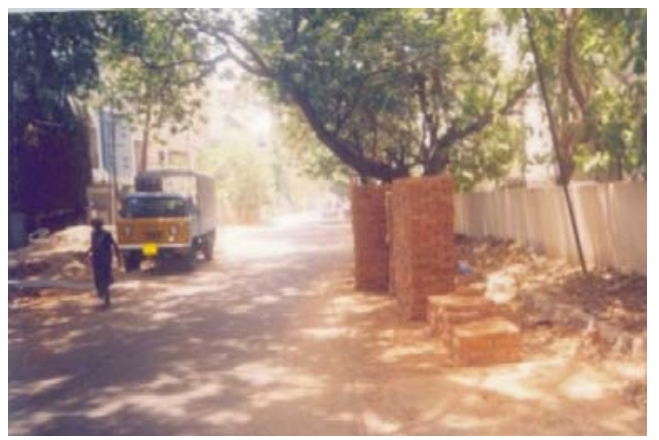

Fig. 3. Gandhi Nagar - Obstacles

"However did it come to this?" (Gilmour, David (Pink Floyd) 1996) 


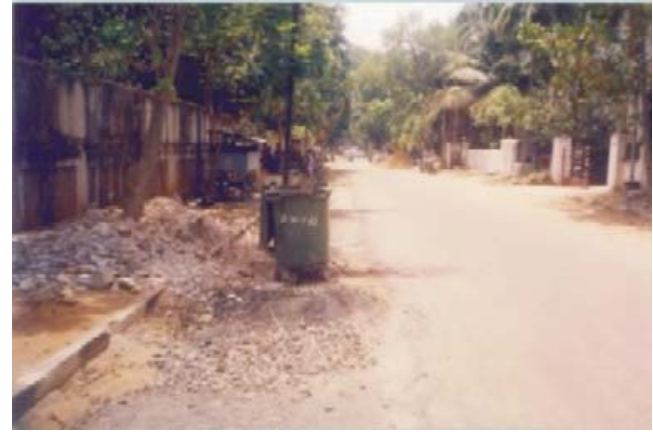

Fig. 4. Lack of maintenance

Many areas could easily be much more pedestrian friendly than they are at present. Pedestrian streets should be extended; through-traffic excluded and traffic-calming techniques employed to reduce the hazards and intrusion of motorized vehicles. Waiting times on pedestrian green phases at road intersections should be kept to a minimum. Total exclusion of traffic is not always a good thing - some traffic can give life and vitality to a city. Streets can be successfully shared by pedestrians and vehicles.

Unless some limit is placed upon traffic volume and its freedom of movement, the destruction of streets and squares as places of social contact will continue - a process that will be accompanied by the degradation of local environmental quality. Thus it is imperative that we address the issue of people-friendly urban areas as early as possible in order to arrest the slide of our urban spaces into vehicular chaos and reclaim our cities for ourselves which is what they were initially meant for.

As Jane Jacobs said "Streets and their sidewalks, the main public places of a city, are its most vital organs. Think of a city and what comes to mind? Its streets." (Jacobs, Jane 1961)

Streets function as Utilitarian equipment, Cultural manifestation, and Local focal points. ( Kroll, J. 2001) These three principal street functions provide various stages for the personal experience of walking. This personal experience takes place in a physical, social, and cultural milieu. Any method that attempts to evaluate this multifaceted personal experience should be equally rich in analytical rigor and insight. Currently available methodologies of assessing service levels for pedestrians are unable to analyze the entire spectrum of the walking experience.

\section{OBJECTIVES}

To highlight issues relating to pedestrian facility planning.
- To look at alternative approaches to pedestrian space standards vis-à-vis IRC guidelines.

- Areport of the existing status of pedestrian facilities.

- Analysis of the existing facilities from a qualitative viewpoint.

\section{ISSUES}

These are a few fundamental questions which could be categorized as various issues relating to pedestrian spaces:

- Issues relating to visual and sensory perception, imageability and aesthetic impact.

- How does one evaluate the quality of a pedestrian environment?

- Does the introduction of a pedestrian area help to improve the imageability and quality of life of an urban area?

- Does the Architectural environment influence the quality and success of a pedestrian area?

2. Issues relating to climate, vegetation and topography.

- How does climate and vegetation exert an impact on the usage of pedestrian areas?

- How does topography of an area influence the usage of a pedestrian area?

3. Issues relating to design parameters and standards.

- What are the problems afflicting existing pedestrian areas?

- Are they being effectively used?

- Does the size and function of a city matter with respect to its pedestrian areas?

- How do Land use patterns influence usage of pedestrian areas?

- Should the context (location, land use) determine standards for pedestrian areas and facilities?

4. Issues relating to user-friendliness and pedestrian convenience and satisfaction.

- Can user perception be utilized to frame context specific standards? 
- Can user perception be harnessed to evolve a tool to document the contribution of pedestrian areas to the quality of life of an urban area?

5. Issues relating to social (culture, lifestyle), economic and religious aspects.

- How do we provide the pedestrian his due share of the street?

- How do our culture and lifestyle exert an impact on the usage of pedestrian areas?

- How does the economic condition of an area affect usage of pedestrian areas?

\section{GUIDELINES AND STANDARDS}

A. $I R C$

The Indian Roads Congress (IRC) has stipulated standards for pedestrian facilities like Sidewalks, Guard Rails and Pedestrian Crossings - both at-grade and grade-separated (Indian Roads Congress, 1998). But these lack the "human" element like aesthetics, scale, form and proportion. Pedestrian amenities and street furniture do not find a place in these standards. Context-specific standards according to the location in the city, hierarchy of streets and functions of streets have not been thought of. There have been no comprehensive standards developed for the Indian context especially in metropolitan cities as far as accessibility criteria and pedestrian spaces is concerned.

The IRC guidelines for pedestrian facilities provides details of sidewalks, guard-rails and crossings - at-grade and grade-separated.

\section{Sidewalks:}

a. Sidewalks should be provided on both sides of the road.

b. The width of sidewalks depends upon the expected pedestrian flows, subject to a minimum of 1.5 metres.

Table 1. Width of sidewalks

\begin{tabular}{|c|c|c|}
\hline \multirow{2}{*}{ Width of sidewalk(m) } & \multicolumn{2}{|c|}{ Capacity in no. of persons per hour } \\
\cline { 2 - 3 } & All in one direction & In both directions \\
\hline 1.50 & 1,200 & 800 \\
\hline 2.00 & 2,400 & 1,600 \\
\hline 2.50 & 3,600 & 2,400 \\
\hline 3.00 & 4,800 & 3,200 \\
\hline 4.00 & 6,000 & 4,000 \\
\hline
\end{tabular}

In shopping areas, the width should be increased by 1 metre which is treated as "dead width". Where sidewalks abut buildings and fences, the dead with can be taken as
0.5 metres. For areas of heavy pedestrian activity such as bus stops, railway stations and recreational areas, the width of sidewalks should be suitably increased to account for accumulation of pedestrians.

\section{Guard-rails:}

- Guard-rails could be considered at hazardous locations along straight stretches, at junctions / intersections, near schools, bus stops, stations, subways, over bridges and in central reserves.

\section{Crossings:}

- Cross-walks of width 2.0 to 4.0 metres should be provided at all important intersections and such locations where substantial conflict exists between vehicular and pedestrian movements. They should be at right angles to the carriageway and properly marked.

- Grade-separated crossings are warranted when the volumes of pedestrian and vehicular traffic are very large, vehicular traffic demands uninterrupted flow and at-grade crossings fail to mitigate the problems of pedestrian-vehicle collision.

\section{B. HCM and LOS}

The HCM 2000 defines "Level of Service" as follows: "A qualitative measure describing operational conditions within a traffic stream, based on service measures such as speed and travel time, freedom to maneuver, traffic interruptions, comfort, and convenience (HCM 2000, p. 58.).This definition of level of service applies to all transportation modes, motorized or non-motorized. Walking is treated as a variation of motorized traffic, the transportation modes being separated only by space and time. "The qualitative measures of pedestrian flow are similar to those used for vehicular flow, such as the freedom to choose desired speeds and to bypass others" (HCM 2000, p. 11-1).

The LOS system is remarkable for its lack of relevance to the personal experience of walking. LOS is based on chronological time. The quality of walking is, however, determined to large degree by psychological or perceived time. For instance, a lively and vibrant sidewalk tends to make slow speeds acceptable, even enjoyable. But, according to the HCM methodology - a high crime area, where pedestrians are hardly seen for obvious reasons, provides good LOS.

Thus a pedestrian facility provides a high LOS if few pedestrians are present, and the best possible pedestrian LOS is achieved with one pedestrian present, ornone! 
Rakesh et al : Comfort and the pedestrian environment...

A logical conclusion since pedestrian LOS is operationally defined as freedom to maneuver. This pedestrian perspective is unsettling and grotesque, however, when we want to understand and improve the pedestrian realm from a social, cultural and economic point of view.

\section{ARANYA-Indian standards.}

Architect B.V. Doshi in the Aga Khan Award winning project "Aranya" - a housing project at Indore had developed a "Levels of Accessibility" scale for various

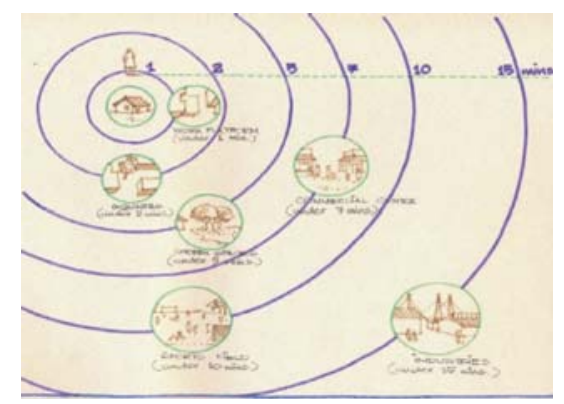

Fig. 5. Aranya - Levels of Accessibility.

facilities, but it was purely restricted to a residential layout. (Vastu-Shilpa Foundation. 1990)

\section{Edward Hall \& Robert Sommer.}

Edward Hall (Hall, Edward T. 1990) in "Hidden Dimension" and Robert Sommer (Sommer, Robert. 1969) in "Personal Space" have developed various standards.

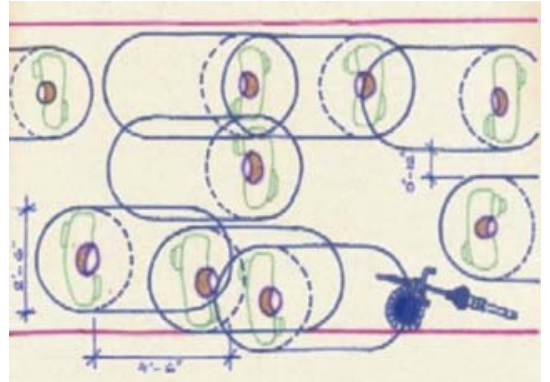

Fig. 6. Typical pedestrian spacing (Desirable moving space bubble 4'-6" long by 2'-2.5'wide)

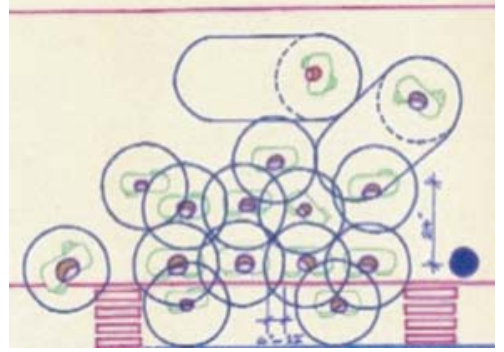

Fig. 7. Waiting at curbs at an intersection

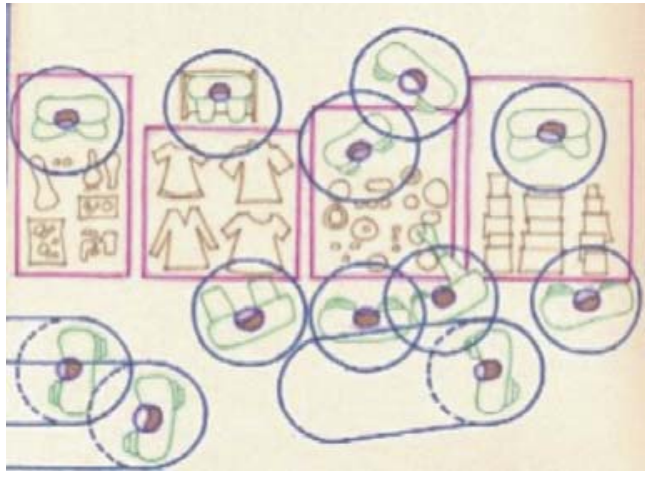

Fig. 8. Gazing at the wares displayed by street vendors



Fig. 9. Listening to street musicians perform

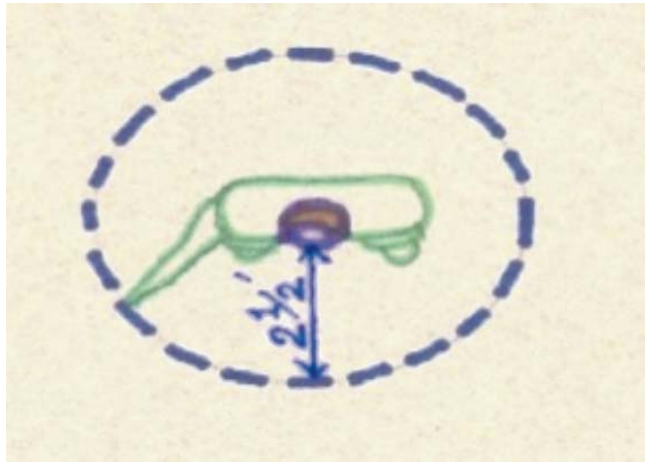

Fig. 10. Personal Standard

These are graphical representations of the basic terminology developed by Robert Sommer in "Personal space" for determining the amount of space people want or need.



Fig. 11. Personal (Close Phase) Average 6 - 8 stt. /person 


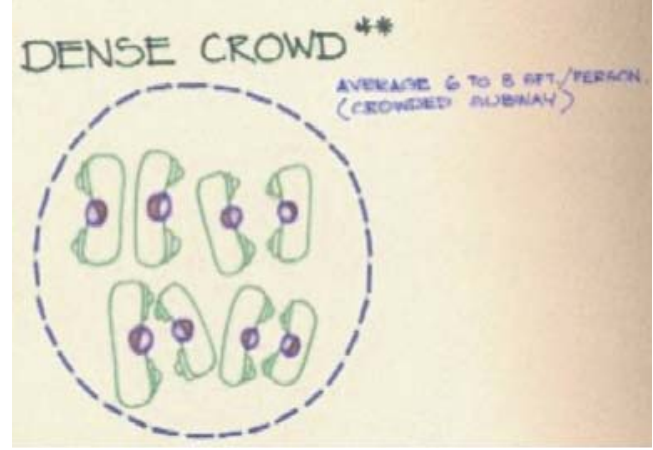

Fig. 12. Dense crowd Average 6 to 8 sft./ person (Crowded subway)

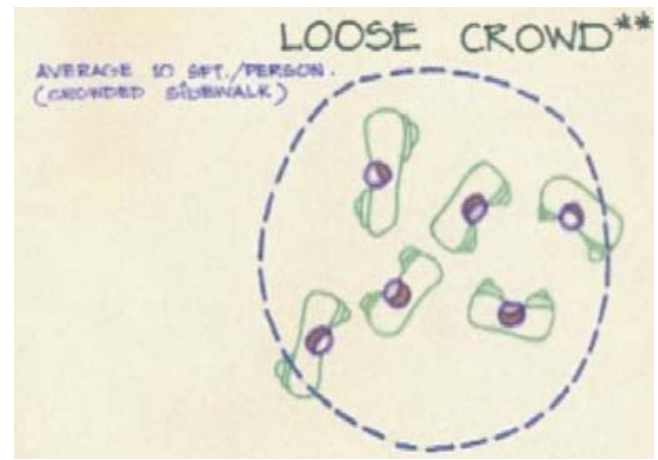

Fig. 13. Loose crowd Average 10 sft. /person (Crowded sidewalk)

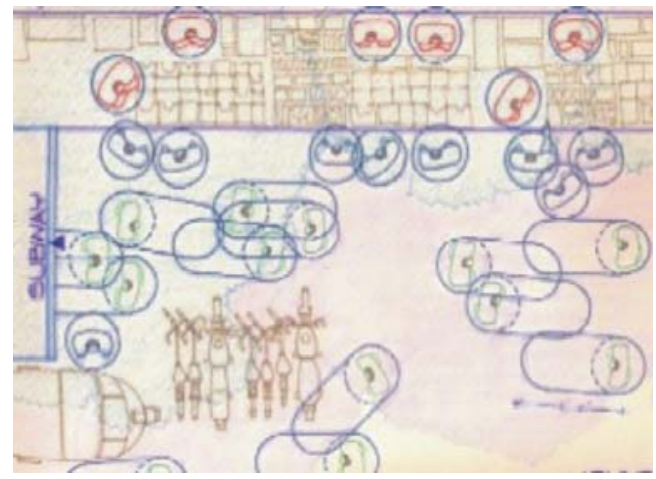

Fig. 14. Mount Road

This sketch uses the same standard for another location-Mount Road.

Here, the trees shade, the subway, G.P.O., Devi theatre complex and consequently the large number of pedestrians - all contribute to the morphology of informal and unauthorized shops. The entire sidewalk is taken up by hawkers. Unauthorized parking of two-wheelers and auto rickshaws also push the pedestrian farther out into the vehicular carriageway.

\section{AMENITIES}

Pedestrian spaces need to be architecturally designed and properly fitted out. According to Anne Shelley, street furnishings are distinctive characteristics and psychologically the design has the effect of a symbol of recognition. Furniture, varied architectural features, play equipment, lighting fixtures, landscaping, fountains and works of art - these elements could visually integrate the entire space.

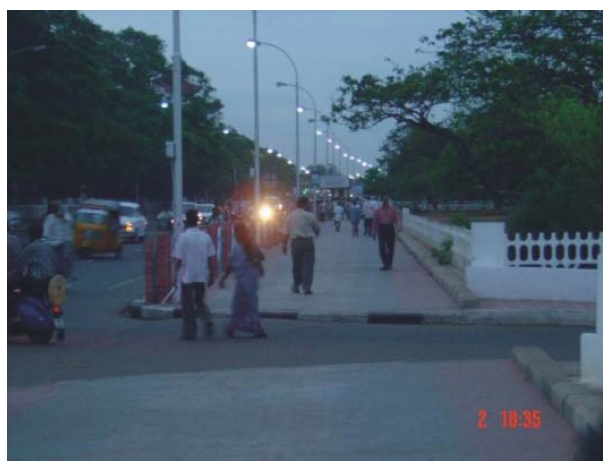

Fig. 15. Marina Beach wide sidewalks

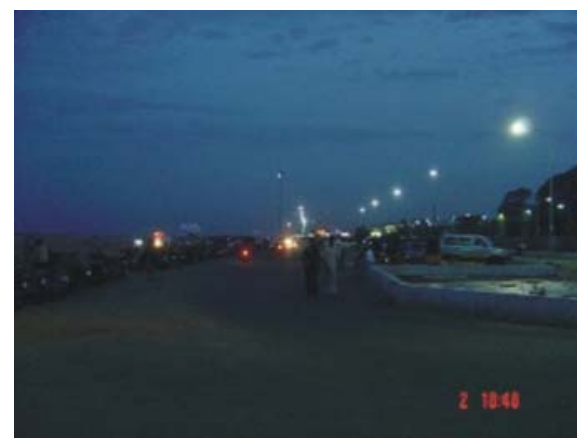

Fig. 16. Lack of pedestrian lights

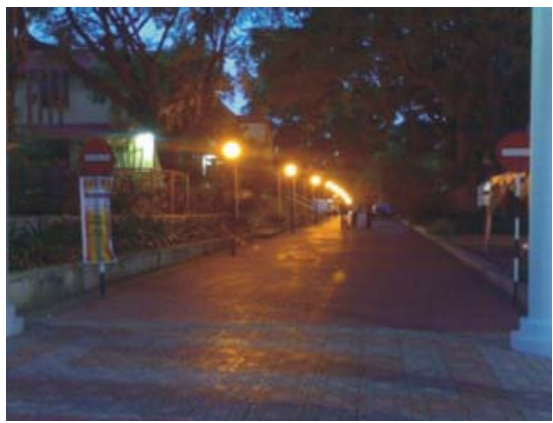

Fig. 17. Pedestrian Lights

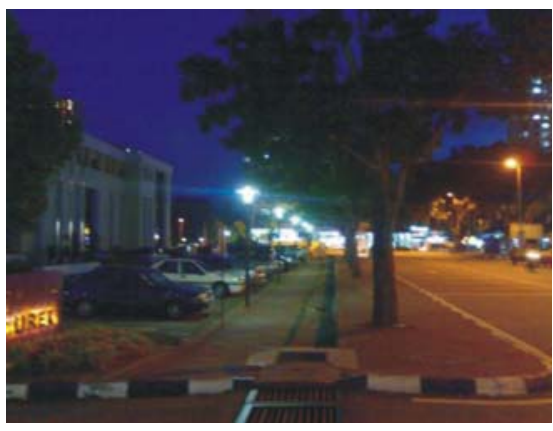

Fig. 18. Lighting detail 




Fig. 19. Street Lighting

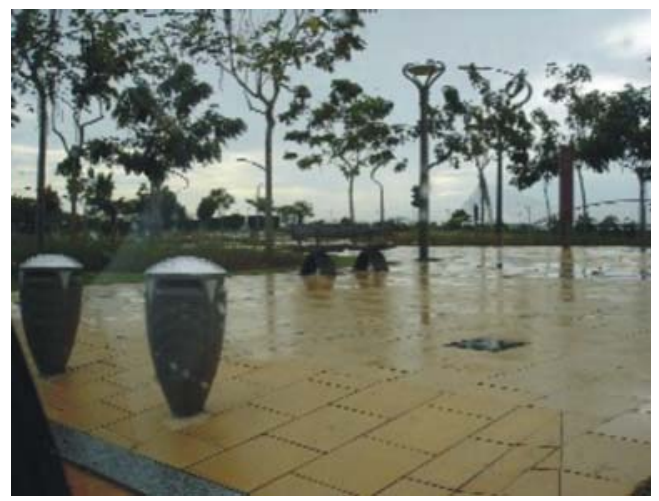

Fig. 20. Street amenties

\section{DESCRIPTION OF THE STUDY AREA}

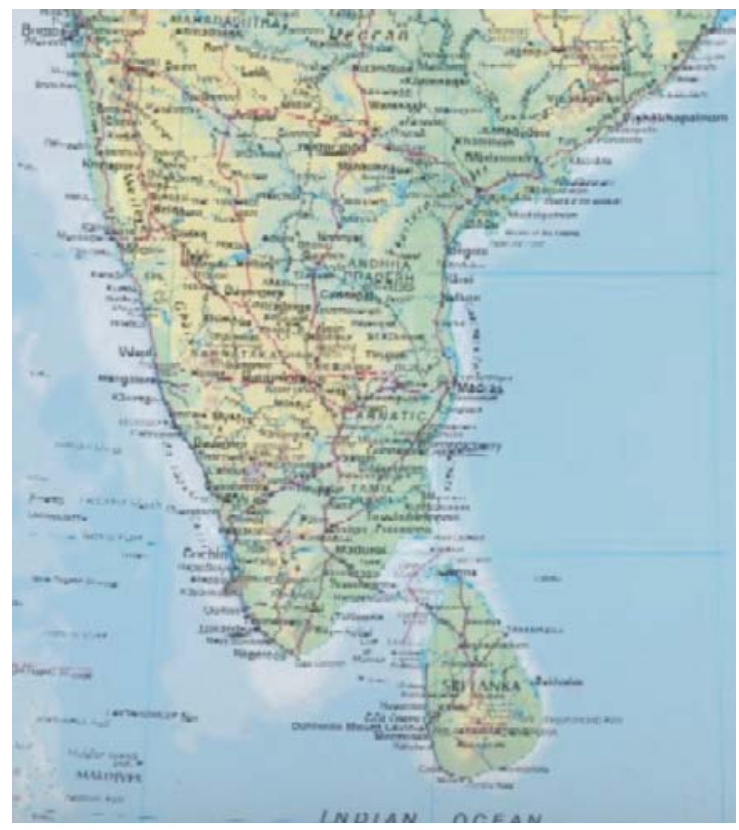

Fig. 21. The southern peninsula of India

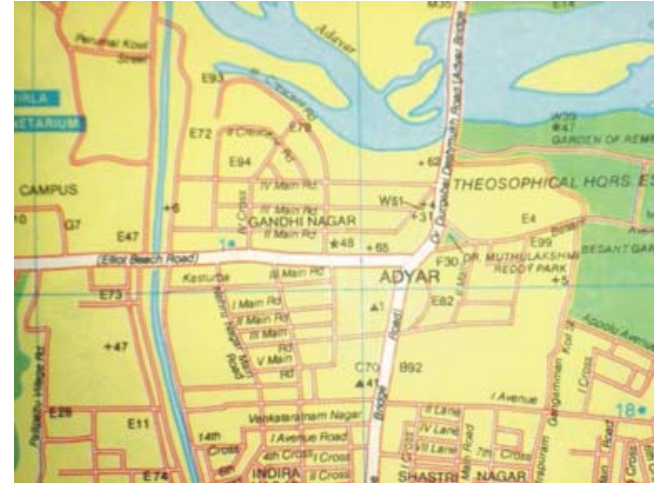

Fig. 22. Adyar - Sardar Patel Road \& Lattice Bridge Road

Adyar has a long and checkered history. In fact it grew with the inception of the Theosophical Society which was started by Madame Blavatsky. The first place to come up in Adyar was Gandhinagar. This fact is quite evident if you look at some of the houses in Gandhinagar. Reminiscent of the British Raj, they are massive structures with long driveways and a huge garden. It is a pity that they are dwindling, giving way to apartments and high rises. Even by 1950 Adyar was only extended to Kasturba Nagar the rest being a jungle. It was only later that development began. The growth has been rapid not to say exponential and Adyar has almost reached its limit. The Adyar Bridge practically connects Adyar to the rest of the city. But there was a time when there was no bridge! The Adyar River was used as a waterway (which is a far cry from its present form!). Boats were used to travel to places like Kotturpuram and the like. In fact, exciting boat races which attracted a huge audience were held annually. From a serene residential area to a bustling commercial centre of South Chennai, Adyar's transformation has been remarkable. Every retail chain, be it groceries, textiles or electronics, has a major presence here. Restaurants catering to the entire spectrum of the population can be found here. Banks, insurance companies and other services also occupy prime office spaces in the area.



Fig. 23. Land-use map pf Adyar 


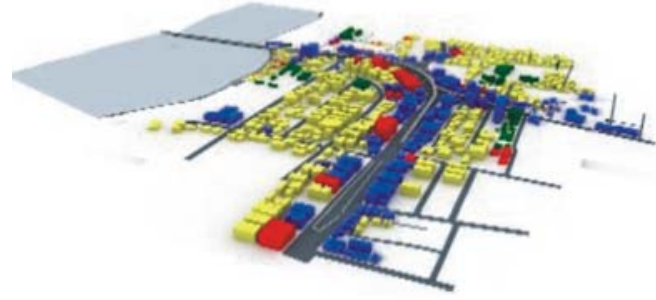

Fig. 24. 3D image of Landuse

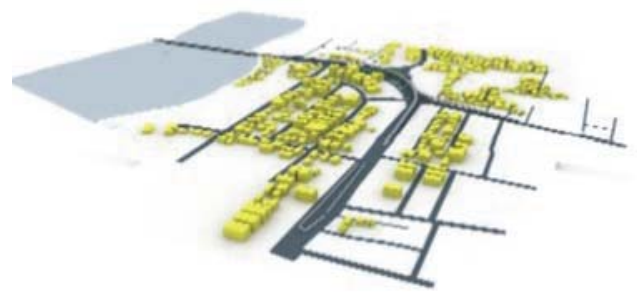

Fig. 25. 3D image of residential areas of Adyar

This sea-change has exacted a cost. The increased traffic which Adyar had to contend with, resulted in the service road abutting Sardar Patel Road to be merged into the main road. A flyover at Adyar Signal resulted in pedestrian walkways being the principal casualty. The stretch of Lattice Bridge road from Adyar Signal to the end of the flyover near the Old Eros theatre is a pedestrian's nightmare come true. Similarly the stretch of road abutting Hotel Coronet and extending to Adyar bakery suffered a reduction in width, as a result of the flyover. Buildings which were witness once to the sedate pace of life in a residential environment, have given way to glitzy shopfronts. The main roads as well as nearby lanes are used for parking by cars and two-wheelers on both sides, thus reducing their carrying capacity. There is a constant flow of people - shoppers, office workers, employees of the commercial establishments, students, and others. But this has not translated into better amenities or facilities for people. Sidewalks are either not maintained properly or are encroached upon, both by private and Government agencies.

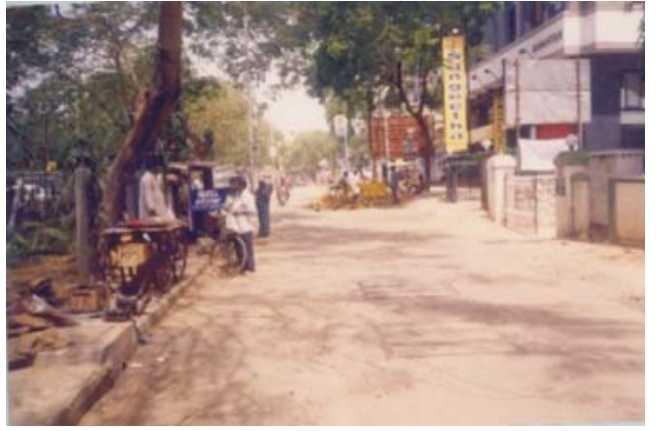

Fig. 26. Vendors encroaching on sidewalks

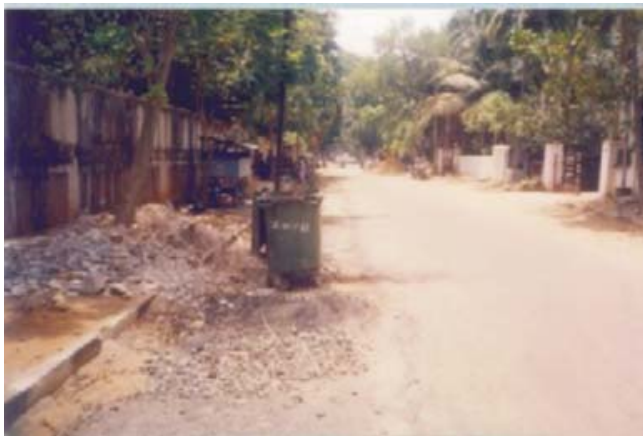

Fig. 27. Other encroachments



Fig. 28. Dumping of Building materials

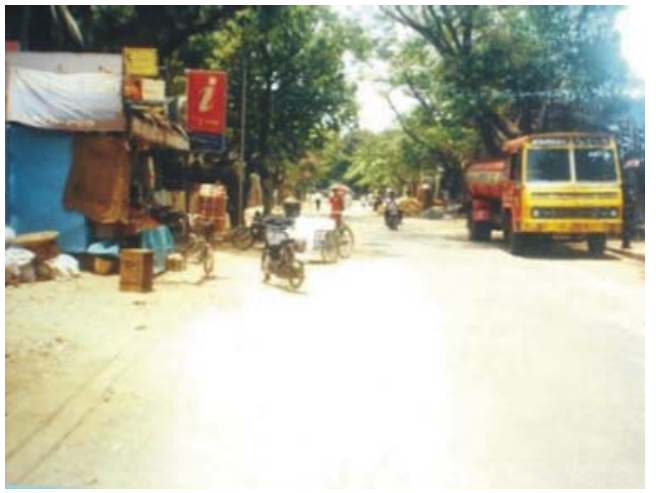

Fig. 29. Shops claiming the sidewalk

Thus, a qualitative assessment needs to be conducted which could highlight factors, such as Safety, Security, Comfort, Convenience, and Attractiveness etc. These environmental factors can greatly influence the 
pedestrians' perceptions of the overall quality of the street environment. These factors can be analyzed in finer detail and an evaluation and grading method can be devised to assess the street. (Sarkar, S. 2002)

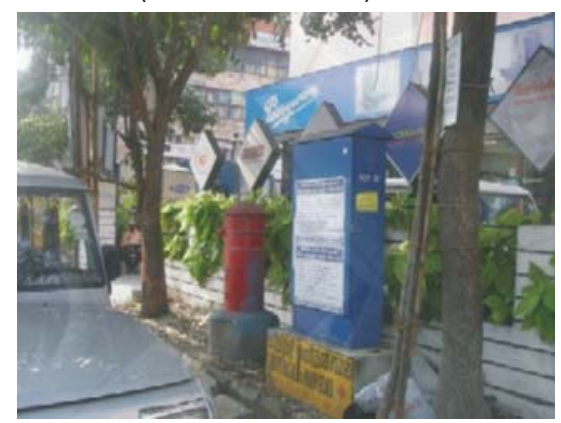

Fig. 30. Official encroachment

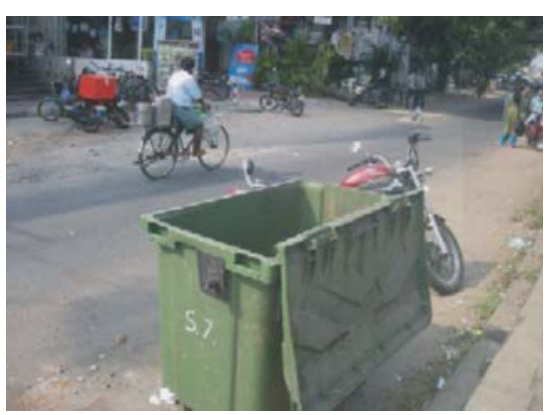

Fig. 31. Lack of maintenance

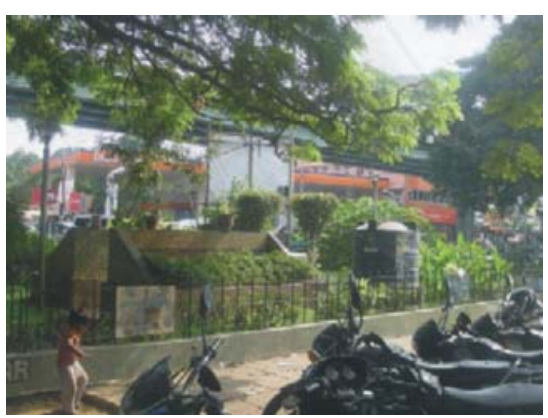

Fig. 32. Well-maintained landscaping



Fig. 33. Official encroachment

\section{EVALUATION}

- A checklist could be drawn up, containing a list of preferred facilities and amenities.

- Ratings for each of these facilities could be given.

- The street could be evaluated against this checklist.

- A simple ratings scale of 1 to 5 is sufficient to accurately cover the range of performance: $5=$ excellent; 4 = good; 3 = average; 2 = poor; 1 = very poor.

\section{A. Facilities and Amenities}

- Sidewalks of adequate width,

- Continuous sidewalks,

- Crossings,

- Curb-cuts,

- Surface design,

- Seating,

- Informal shopping,

- Minor architectural features,

- Recreational equipment,

- Lighting - decorative, flood lighting, illuminated signs, tree top lighting,

- Landscaping,

- Fountains/water bodies,

- Art\&Artifacts-Sculpture, Paintings, etc.

B. Qualities (Allan Jacob)

- enclosure/definition,

- complexity of path network,

- building articulation,

- complexity of spaces,

- transparency,

- buffer, 
shade trees,

overhangs/awnings/varied rooflines, and

physical components / condition.

C. Evaluation

Table 2. Sardar Patel Road

\begin{tabular}{|c|l|c|}
\hline S.No. & \multicolumn{1}{|c|}{ Facility / Amenity } & Rating \\
\hline 1 & Sidewalks of adequate & 2 \\
\hline 2 & Continuous sidewalks & 3 \\
\hline 3 & Crossings & 1 \\
\hline 4 & Curb-cuts & 0 \\
\hline 5 & Surface design & 0 \\
\hline 6 & Seating & 0 \\
\hline 7 & Informal shopping & 0 \\
\hline 8 & Minor architectural & 1 \\
\hline 9 & Recreational & 0 \\
\hline 10 & Lighting & 0 \\
\hline 11 & Landscaping & 0 \\
\hline 12 & Fountains & 0 \\
\hline 13 & Art / Artifacts & 0 \\
\hline
\end{tabular}

Table 3. Lattice Bridge Road

\begin{tabular}{|c|l|c|}
\hline S.No. & Facility / Amenity & Rating \\
\hline 1 & Sidewalks of adequate & 1 \\
\hline 2 & Continuous sidewalks & 4 \\
\hline 3 & Crossings & 2 \\
\hline 4 & Curb-cuts & 0 \\
\hline 5 & Surface design & 0 \\
\hline 6 & Seating & 0 \\
\hline 7 & Informal shopping & 1 \\
\hline 8 & Minor architectural & 1 \\
\hline 9 & Recreational & 0 \\
\hline 10 & Lighting & 0 \\
\hline 11 & Landscaping & 0 \\
\hline 12 & Fountains & 0 \\
\hline 13 & Art / Artifacts & 0 \\
\hline
\end{tabular}

Table 4. Sardar Patel Road

\begin{tabular}{|c|l|c|}
\hline S.No. & Quality attribute & Ratin \\
\hline 1 & enclosure/definition & 3 \\
\hline 2 & complexity of path network & 1 \\
\hline 3 & building articulation & 2 \\
\hline 4 & complexity of spaces & 1 \\
\hline 5 & transparency & 1 \\
\hline 6 & buffer & 0 \\
\hline 7 & shade trees & 1 \\
\hline 8 & overhangs/awnings/varied & 0 \\
\hline 9 & physical & 2 \\
\hline
\end{tabular}

Table 5. Lattice Bridge Road

\begin{tabular}{|c|l|c|}
\hline S.No. & \multicolumn{1}{|c|}{ Quality attribute } & Rating \\
\hline 1 & enclosure/definition & 3 \\
\hline 2 & complexity of path & 1 \\
\hline 3 & building articulation & 3 \\
\hline 4 & complexity of spaces & 1 \\
\hline 5 & transparency & 1 \\
\hline 6 & buffer & 0 \\
\hline 7 & shade trees & 1 \\
\hline 8 & overhangs/awnings/varied & 0 \\
\hline 9 & physical & 1 \\
\hline
\end{tabular}

\section{CONCLUSION}

This evaluation can be used to determine what specific elements or aspects in the pedestrian environment are deficient and to what extent. Remedial measures could then be undertaken to improve pedestrian comfort.

\section{ACKNOWLEDGEMENT}

The support of the architecture batch of 2004-09, Sathyabama University is gratefully acknowledged.

\section{REFERENCES}

[1] Buchanan, C. (1963), Traffic in Towns, The Buchanan Report, Penguin, Harmondsworth, pp.56-57

[2] Burden, Dan, (1996), Walkable and BicycleFriendly Communities, Florida Dept. of Transportation.

[3] C. Alexander and others (1977), A Pattern Language, Oxford University Press, New York .

[4] Fruin, J.J. (1971), Pedestrian: planning and design, Metropolitan Association of Urban Designers and Environmental Planners, Inc., New York.

[5] Guidelines for Pedestrian Facilities - IRC : 103 -(1998), The Indian Roads Congress, New Delhi.

[6] Hall, Edward T.(1990), The hidden dimension, Anchor Books (Doubleday), New York.

[7] Jacobs, Allen. (1993), Great Streets, MIT Press, Boston.

[8] Jacobs, Jane.(1961), The Death and Life of Great American Cities, Random House, New York, p.39. 
[9] Khisty, C.J.(1994), Evaluation of pedestrian facilities: beyond the level-of-service concept. Transportation Research Record 1438.

[10] Kroll, J. (2001), Moving About in a Technological World: A Hermeneutic-Phenomenological Inquiry of Urban Streets and Freeways as Public Architecture, Ph.D. dissertation, Department of Architecture, University of California, Berkeley.

[11] Lynch, Kevin.(1960), Image of the city, MIT Press, p.9

[12] Norberg-Schulz, C. (1971), Existence, Space and Architecture, Studio Vista, London, p.18.

[13] Sarkar, S. (1995), Macro level and micro level evaluation of pedestrian networks.

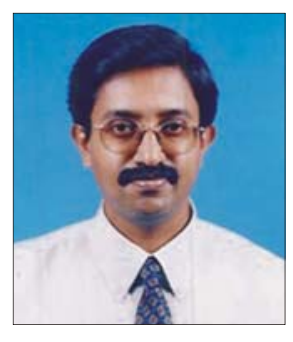

Mr. K. S. Rakesh is a Research Scholar at The School of Architecture and Planning, Anna University, Chennai and an Assistant Professor at the Department of Architecture, Sathyabama University, Chennai. His field of research is "Pedestrian spaces in urban areas". A post-graduate from The School of Architecture and Planning, Anna University, Chennai, his areas of interest are Climatic Design, Contemporary Architecture and Urban Design. 